\title{
Effectiveness of cartoon animation video on pain during venepuncture among 3-6 year old children
}

\author{
Swati Chavan ${ }^{1}, *$ Prakash Naregal $^{1}$ \\ Sri Lanka Journal of Child Health, 2021; 50(2): 299-305
}

\begin{abstract}
Background: Distraction techniques are suitable measures for pain alleviation in young children during routine invasive procedures like venepuncture, serving as a positive stimulus drawing attention away from a painful experience.
\end{abstract}

Objectives: To evaluate the effectiveness of cartoons animation videos as a pain alleviant during venepuncture along with delineating association of pain with selected variables.

Method: This study followed a quasi-experimental design to monitor 60 children in the age group of 36 years selected by non-probability purposive sampling technique. The experimental and control group were composed of 30 children each. Baseline Proforma and an r-FLACC pain scale were used to measure and gather data. Cartoon animation video as an intervention was administered to the experimental group participants undergoing venepuncture and its effectiveness was estimated using an unpaired t-test. Association between pain perception and selected variables was analysed by a Chi-square test.

Results: Divergence between pain perception among the control and experimental group was highlighted by the mean pain scores of $2.9 \pm 0.25$ and $2.3 \pm 0.46$ respectively $(p<0.001)$. Effectiveness of cartoon animation videos as a distraction technique for pain alleviation was found to be significant $(p<0.01)$. No significant association was found between the level of pain perceived by preschool children during venepuncture and the selected variables $(\mathrm{p}>0.05)$

${ }^{1}$ Krishna Institute of Nursing Sciences, Karad,
Maharashtra, India
${ }^{*}$ Correspondence: prakash.naregal20@gmail.com
iD https://orcid.org/0000-0001-9952-504X
(Received on 27 May 2020: Accepted after revision on 24 July 2020)

The author declares that there are no conflicts of interest

Personal funding was used for the project.

Open Access Article published under the Creative

Commons Attribution CC-BY (c) (i) License
Conclusions: Cartoon animation video was effective as a pain alleviant during venepuncture. No significant association was found between the level of pain perceived by the 3-6 year old children during venepuncture and the selected variables.

DOI: http://dx.doi.org/10.4038/sljch.v50i2.9577

(Key words: Child, pain perception, phlebotomy, preschool)

\section{Introduction}

Pain is often regarded as a subjective sensation having physiological, psychological and emotional implications for an individual ${ }^{1}$. In young children who undergo invasive procedures such as venepuncture at a tender age, the procedural pain perceived, not only shapes their present experience but also their future encounters with pain ${ }^{2}$. Rapid heartbeat, elevated blood pressure, skin irritation and insomnia experienced due to venepuncture can advance into chronic ailments of a nutritional, cardiovascular or respiratory nature warranting longer hospitalisation and poor attendance at school $^{3}$. The intravenous (IV) method of blood sampling or administration of therapeutic agents by piercing the venous wall, referred to as venepuncture, is the most common procedure undergone by children. Although around $83 \%$ of 3 6 year olds who have undergone venepuncture reported considerable distress, less than $10 \%$ of venepuncture procedures are supplemented with age-appropriate management strategies ${ }^{2}$. Toys, pictorial books, kaleidoscope, video games and blowing bubbles are a few examples of distraction strategies tailored to manage pain in young children ${ }^{4}$.

Perception of pain is said to vary on account of factors such as age, sex, culture, temperament, cognitive aptitude, parental care and previous experiences $^{5}$. Anticipatory anxiety plays an important role in deciding the perception of pain manifesting as behavioural distress and noncompliance that further intensifies their pain ${ }^{5,6}$. Inadequate or unmanaged procedural pain from venepuncture in children is linked to greater intensity and duration of discomfort as well as lifelong phobias towards medical interventions and care $^{2}$. Alleviation of procedural pain plays an important role in improving the performance of healthcare workers, treatment outcome and the 
overall satisfaction of the patients which is achieved using pharmacologic and nonpharmacologic methods ${ }^{5}$. Pharmacological aids in the form of pre-procedural local analgesics, though commonly used, have not been able to curtail the pain and stress experienced by children during venepunctures $^{7,8}$. Non pharmacologic interventions in use include hypnosis, cognitive behavioural therapy and physical methods such as application of hot and cold packs which help in ameliorating the severity of pain percieved ${ }^{9,10}$. However, their transient effect, time consuming nature, in addition to the need for skilled manpower and monetary resources constitute the major drawbacks of such non pharmacologic therapies.

On the other hand, distraction technique, as a nonpharmacological intervention, serves to assuage procedural pain in children by diverting their attention towards pleasant stimuli that effectuates release of endorphins and neuromodulators in the brainstem that block pain receptors ${ }^{1}$. Cartoon animations based on distraction strategies can function as effective, inexpensive, and easily administrable procedural pain therapy for children, the results for which are inconsistent in the literature ${ }^{2,4}$. Cartoon animations often engage multiple senses, carry a sense of familiarity and can evoke enthusiasm among young children almost instantaneously in comparison to other distraction strategies.

\section{Objectives}

This study was aimed at determining the efficacy of cartoon animation videos in ameliorating pain in 36 year old children by assessing the pain experienced during venepuncture, as well as delineating the factors influencing pain perception.

\section{Method}

This quasi-experimental study was conducted in the paediatric ward of a tertiary care centre from December 2017 to January 2018. The study adopted a balanced-comparative case-control design. All paediatric patients aged between 3-6 years who were conscious, mentally alert, scheduled for venepuncture and bereft of any critical illness or cognitive disabilities were included. Meanwhile, children who were critically ill and intellectually challenged were excluded. Competent authorities of the hospital and parents or relatives of the enrolled participants were approached for their permission and informed consent respectively.

In this study, 60 children were divided into two groups namely an intervention group and a control group consisting of 30 children each using nonprobability purposive sampling technique. A sample size of 6 with $95 \%$ confidence level and
$80 \%$ power was suggested by the mean and standard deviation formula based on previous studies, where 1-alpha/2 and 1-beta represented type 1 error and power of the study respectively ${ }^{9,10}$. Hence, the sample size of 30 was selected in each group to enhance the validity of the observations made. The intervention group was shown cartoon video during venepuncture while the control group did not receive any such treatment during the invasive procedure of venepuncture.

\section{Data collection and procedure}

Pain was depicted by Revised Face, Legs, Activity, Cry and Consolability (r-FLACC) scores and the effectiveness of the treatment was evaluated in terms of abatement of pain response demonstrated by children after the intervention, as measured by $\mathrm{r}$ FLACC scale ${ }^{11}$. The r-FLACC scale assesses pain across five paradigms of observation i.e. face, legs, activity, crying and consolability with a higher score representative of increased severity of pain. Each of these five variables has three scores, 0, 1 and 2 . Overall pain score of 0 indicates relaxed and comfortable status of the child, 1-3 indicates mild discomfort, 4-6 implies moderate pain whereas scores between 7-10 denote severe pain or discomfort or both ${ }^{1}$.

The protocol followed began with the researchers introducing themselves to the children and parents, explaining the purpose and procedure of the study, obtaining formal written consent of parents and hand washing. Cartoon animations were played during venepuncture and subsequent pain responses of children were noted by the researcher.

Medical history of participants encompassing records of previous hospitalization, previous exposure to painful procedures, site and number of venepuncture attempted were inquired and noted on a Demographic Proforma sheet along with demographic characteristics such as age and gender.

Ethical issues: Ethical clearance was obtained from Institutional Ethics Committee of the Krishna Institute of Nursing Sciences, Karad, Maharashtra, India (Reg. No: ECR/ 307/ Inst/ MH/ 2013/RR-16). Written informed consent was obtained from the parents of the children involved in the study.

Statistical analysis: Data was also entered and stored in MS Excel 2011. Statistical analysis was carried out using R-Software. Descriptive mean, median and standard deviation statistics analysed demographic variables and pain scores of children. Inferential statistics included an unpaired t-test to test the effectiveness of cartoon animation videos on ameliorating pain response and a Chi-square test to find the association between pain scores 
observed and select data collected from patients. A $p$-value less than 0.05 was considered to reflect statistical significance.

\section{Results}

The following study was conducted on 60 children undergoing venepuncture, with experimental and control groups comprising 30 children each, and potential factors that could influence their pain sensation were taken into account (Table 1).

Table 1: Distribution of demographic variables and clinical history

\begin{tabular}{|c|c|c|}
\hline Variables & $\begin{array}{c}\text { Experimental group }(n=30) \\
n(\%)\end{array}$ & $\begin{array}{c}\text { Control group }(n=30) \\
n(\%)\end{array}$ \\
\hline $\begin{array}{c}\text { Age (years) } \\
3 \\
4 \\
5 \\
6\end{array}$ & $\begin{array}{l}12(40.0) \\
05(16.7) \\
06(20.0) \\
07(23.3)\end{array}$ & $\begin{array}{l}13(43.3) \\
08(26.7) \\
05(16.7) \\
04(13.3)\end{array}$ \\
\hline $\begin{array}{c}\text { Gender } \\
\text { Female } \\
\text { Male }\end{array}$ & $\begin{array}{l}13(43.3) \\
17(56.7)\end{array}$ & $\begin{array}{l}16(53.3) \\
14(46.7)\end{array}$ \\
\hline $\begin{array}{c}\text { Hospitalization } \\
\text { No } \\
\text { Yes }\end{array}$ & $\begin{array}{l}10(33.3) \\
20(66.7)\end{array}$ & $\begin{array}{l}13(43.3) \\
17(56.7)\end{array}$ \\
\hline $\begin{array}{c}\text { Exposure } \\
\text { No } \\
\text { Yes }\end{array}$ & $\begin{array}{l}10(33.3) \\
20(66.7\end{array}$ & $\begin{array}{l}13(43.3) \\
17(56.7)\end{array}$ \\
\hline $\begin{array}{c}\text { Site } \\
\text { Cephalic } \\
\text { Dorsal } \\
\text { Radial } \\
\text { Superficial }\end{array}$ & $\begin{array}{c}02(06.7) \\
09(30.0) \\
0 \\
19(63.3)\end{array}$ & $\begin{array}{l}07(23.3) \\
07(23.3) \\
01(03.3) \\
15(50.0)\end{array}$ \\
\hline $\begin{array}{c}\text { Attempts } \\
1 \\
2\end{array}$ & $\begin{array}{l}19(63.3) \\
11(36.7)\end{array}$ & $\begin{array}{l}16(53.3) \\
14(46.7)\end{array}$ \\
\hline
\end{tabular}

Majority of study group and control group children were 3 years old. Gender wise distribution revealed male predominance $(56.7 \%)$ in study group and female predominance $(53.3 \%)$ in the control group. About $66.7 \%$ and $56.7 \%$ of the study group and control group respectively had a previous history of hospitalisation. A similar trend was noticed in reference to children having been exposed to the cannulation procedure previously. Most of the study group participants $(63.3 \%)$ had undergone venepuncture at the site of superficial vein. In the control group however, parity was observed between the dorsal site of venepuncture $(23.3 \%)$ and that of the radial $(3.3 \%)$ and cephalic vein $(23.3 \%)$. In both the study group and control group a majority of children underwent venepuncture in a single attempt i.e. $63.3 \%$ and $53.3 \%$ respectively.

Table 2 illustrates the categories of pain scores observed across both groups as measured by $\mathrm{r}$ FLACC scale during venepuncture.

Table 2: Categories of pain scores recorded during venepuncture in control and experimental groups

\begin{tabular}{|l|c|c|}
\hline \multicolumn{1}{|c|}{ Pain score } & $\begin{array}{c}\text { Experimental Group } \\
\mathbf{n}(\mathbf{\%})\end{array}$ & $\begin{array}{c}\text { Control Group } \\
\text { n (\%) }\end{array}$ \\
\hline Mild pain (0-2) & 0 & 0 \\
\hline Moderate pain (4-6) & $21(70.0)$ & $02(06.7)$ \\
\hline Severe pain (8-10) & $09(30.0)$ & $28(93.3)$ \\
\hline
\end{tabular}

In the control group, $93.3 \%$ of children experienced severe pain; however in the study group 70\% children perceived moderate level of pain with only $30 \%$ experiencing severe pain. None of the children included in the study reported a mild level of pain. Overall, a difference of $0.6 \pm 0.21$ was noticed in the mean pain scores with standard deviation across the groups where the study group had a mean of 2.3 \pm 0.46 in comparison to the control group's higher mean pain score of $2.9 \pm 0.25$. The effectiveness of cartoon animation videos on alleviation of pain perceived by 3-6 year olds during venepuncture was found to be highly significant $(\mathrm{p}<0.001)$ as per results of an unpaired t-test. 
Chi-square test demonstrated the absence of a significant association between observed pain scores of participants and their corresponding demographic and clinical variables $(p>0.05)$. Hence factors like age, gender, previous instances of hospitalization, exposure to painful procedures, site and number of venepuncture attempts were not found to influence pain perception of 3-6 year olds undergoing venepuncture as shown in Tables 3 and 4.

Table 3: Association of pain scores and selected variables among the study group

\begin{tabular}{|c|c|c|c|c|c|}
\hline \multirow[t]{2}{*}{ Demographic variables } & \multicolumn{2}{|c|}{ Category of pain } & \multirow[t]{2}{*}{ Total } & \multirow[t]{2}{*}{ Chi-square } & \multirow{2}{*}{$\begin{array}{c}\text { P-value } \\
\text { (simulated) }\end{array}$} \\
\hline & Moderate & Severe & & & \\
\hline $\begin{array}{l}\text { Age group } \\
3 \text { years } \\
4 \text { years } \\
5 \text { years } \\
6 \text { years }\end{array}$ & $\begin{array}{l}8 \\
3 \\
4 \\
6\end{array}$ & $\begin{array}{l}4 \\
2 \\
2 \\
1\end{array}$ & $\begin{array}{l}12 \\
5 \\
6 \\
7\end{array}$ & 1.1565 & 0.8171 \\
\hline $\begin{array}{l}\text { Gender } \\
\text { Female } \\
\text { Male }\end{array}$ & $\begin{array}{l}10 \\
11\end{array}$ & $\begin{array}{l}3 \\
6\end{array}$ & $\begin{array}{l}13 \\
17\end{array}$ & 0.52359 & 0.6907 \\
\hline $\begin{array}{l}\text { Previous hospitalization } \\
\text { No } \\
\text { Yes }\end{array}$ & $\begin{array}{c}9 \\
12\end{array}$ & $\begin{array}{l}1 \\
8\end{array}$ & $\begin{array}{l}10 \\
20\end{array}$ & 2.8571 & 0.1974 \\
\hline $\begin{array}{l}\text { Previous exposure } \\
\text { No } \\
\text { Yes } \\
\end{array}$ & $\begin{array}{c}9 \\
12\end{array}$ & $\begin{array}{l}1 \\
8\end{array}$ & $\begin{array}{l}10 \\
20\end{array}$ & 2.8571 & 0.1974 \\
\hline $\begin{array}{l}\text { Vein puncture sites } \\
\text { Cephalic } \\
\text { Dorsal } \\
\text { Radial }^{\#} \\
\text { Superficial Dorsal }\end{array}$ & $\begin{array}{c}1 \\
8 \\
0 \\
12 \\
\end{array}$ & $\begin{array}{l}1 \\
1 \\
0 \\
7\end{array}$ & $\begin{array}{c}2 \\
9 \\
0 \\
19 \\
\end{array}$ & 2.3336 & 0.2549 \\
\hline $\begin{array}{l}\text { Attempts } \\
1 \\
2 \\
\end{array}$ & $\begin{array}{c}13 \\
8\end{array}$ & $\begin{array}{l}6 \\
3 \\
\end{array}$ & $\begin{array}{l}19 \\
11\end{array}$ & 0.061517 & $\sim 1$ \\
\hline
\end{tabular}

\# Radial site was not considered during Chi-square analysis due to lack of values. ${ }^{*} p$ less than 0.05 was considered significant.

Table 4: Association of pain scores and selected variables among the control group

\begin{tabular}{|c|c|c|c|c|c|}
\hline \multirow[t]{2}{*}{ Demographic variables } & \multicolumn{2}{|c|}{ Category of pain } & \multirow[t]{2}{*}{ Total } & \multirow{2}{*}{ Chi-square } & \multirow{2}{*}{$\begin{array}{c}\text { P-value } \\
\text { (simulated) }\end{array}$} \\
\hline & Moderate & Severe & & & \\
\hline $\begin{array}{l}\text { Age group } \\
3 \text { years } \\
4 \text { years } \\
5 \text { years } \\
6 \text { years } \\
\end{array}$ & $\begin{array}{l}0 \\
1 \\
1 \\
0\end{array}$ & $\begin{array}{c}13 \\
7 \\
4 \\
4 \\
\end{array}$ & $\begin{array}{l}13 \\
8 \\
5 \\
4 \\
\end{array}$ & 3.0804 & 0.4273 \\
\hline $\begin{array}{l}\text { Gender } \\
\text { Female } \\
\text { Male }\end{array}$ & $\begin{array}{l}2 \\
0\end{array}$ & $\begin{array}{l}14 \\
14 \\
\end{array}$ & $\begin{array}{l}16 \\
14 \\
\end{array}$ & 1.875 & 0.4773 \\
\hline $\begin{array}{l}\text { Previous hospitalization } \\
\text { No } \\
\text { Yes }\end{array}$ & $\begin{array}{l}0 \\
2 \\
\end{array}$ & $\begin{array}{l}17 \\
11 \\
\end{array}$ & $\begin{array}{l}17 \\
13 \\
\end{array}$ & 2.8022 & 0.1759 \\
\hline $\begin{array}{l}\text { Previous exposure } \\
\text { No } \\
\text { Yes }\end{array}$ & $\begin{array}{l}0 \\
2\end{array}$ & $\begin{array}{l}17 \\
11\end{array}$ & $\begin{array}{l}17 \\
13\end{array}$ & 2.8022 & 0.1759 \\
\hline $\begin{array}{l}\text { Vein puncture sites } \\
\text { Cephalic } \\
\text { Dorsal } \\
\text { Radial }^{\#} \\
\text { Superficial Dorsal } \\
\end{array}$ & $\begin{array}{l}0 \\
1 \\
0 \\
1 \\
\end{array}$ & $\begin{array}{c}7 \\
6 \\
1 \\
14 \\
\end{array}$ & $\begin{array}{c}7 \\
7 \\
1 \\
15 \\
\end{array}$ & 1.2245 & $\sim 1$ \\
\hline $\begin{array}{l}\text { Attempts } \\
1 \\
2\end{array}$ & $\begin{array}{l}0 \\
2\end{array}$ & $\begin{array}{l}16 \\
12\end{array}$ & $\begin{array}{l}16 \\
14\end{array}$ & 2.449 & 0.1999 \\
\hline
\end{tabular}

* p less than 0.05 was considered significant.

\section{Discussion}

Coping mechanisms for pain develop with age and experience. However, in the case of young children who are exposed to invasive procedures like venepuncture but are too young to exhibit behavioural and cognitive coping mechanisms, 
distraction technique is better suited ${ }^{11}$. Cartoon animation videos shown during venepuncture were found to be highly effective in alleviating pain response among pre-schoolers. Pain was independent of the array of variables scrutinized as potential indicators of pain.

Analysis of the demographic data collated by this study reflects that a majority of the cohort were 3 years old. Slight preponderance of female participants over male participants was noticed. A similar study conducted by Devi CP, et $a l^{12}$ on the effect of cartoon animation video during venepuncture on pain related responses in preschool age children reported most children were in the 3-4 years age group. However, contrary to the present study majority were males in both the experimental and control groups, where maximum children had no previous experience of venepuncture or hospitalization. These differences may arise on account of varied healthcare seeking behaviour among populations studied, especially in areas where neglect of girl child is prevalent.

In this quasi experimental study, the positive impact of cartoon animation videos on lowering pain perception was highlighted by the lower mean pain score of the experimental group. These findings are aligned with the results of a study by James $\mathrm{J}$, et $a l^{5}$ who inferred cartoon animations to be an effective pain alleviation strategy among preschoolers undergoing venepuncture. This inference was based on sharp differences noted in the mean pain score during venepuncture with animated cartoon $(6.24 \pm 2.09)$ as compared to routine care $(8.06 \pm 1.70)(\mathrm{p}<0.001)$. Findings of Kaur B, et al ${ }^{13}$ also echoed the same inference by reporting statistically significant differences between the mean post assessment pain score value of experimental and control group $(\mathrm{p}<0.005)$ preceding, during and following intravenous injection. Hence, it is advisable that the continuous engagement provided by cartoon animations to young children must not only be limited to the duration of the procedure but should be ideally provided before, during and until a short while after. Similarly, a study by Shrestha $\mathrm{R}$ et $a l^{4}$ stated cartoon animations to be an effective diversion therapy for reducing pain during venepuncture in pre-schoolers $(p<0.05)$. The difference in the mean pain scores of the two groups measured by the $r$ FLACC scale were found to be highly significant $(p<0.001)$ in the present study as evidenced by the fact that a majority of the experimental group experienced moderate pain contrary to severe pain perceived in the control group ${ }^{1}$. Variation in the mean pain scores of the present study and those of previous studies can be attributed to the experience and skill of the phlebotomist performing the procedure and the receptiveness of children based on the cartoon animation chosen as intervention.

The study by Maharjan $\mathrm{S}$, et $a l^{1}$ demonstrated a scenario where in the experimental group 56.7\% subjects recorded pain scores between 4-6 (moderate pain) and $43.3 \%$ had scores in the 7-10 range (severe pain) whilst in the control group all children experienced severe pain, with pain scores of $7-10^{1}$. In the present study, a more drastic difference in seen in reference to the pain perceived wherein $70 \%$ of the study group experienced moderate pain, contrary to $93.3 \%$ of the control group experiencing severe pain. A study by Noel $\mathrm{M}$, et $a l^{14}$ presents a contradictory finding where distraction strategy played a role in 5-10 year olds forming accurate memories of the experience but was not found to influence feelings of fear, anxiety and distress among them. The distraction strategy employed in the latter study consisted of nonprocedural talk. This indicates that not all distraction strategies have a similar effect and mechanism of functioning. Therefore, selection of distraction tools should be contingent upon the age, interests, and levels of engagement offered by them to the children ${ }^{14}$.

There persists dissonance in the scientific literature on factors capable of influencing pain perception among children. Some studies have shown that age plays a role in dictating pain as an outcome of venepuncture $^{10,15}$, whereas another set of studies by James $\mathrm{J}$, et $a l^{5}$ and Gandhar SS, et $a l^{16}$ have shown pain perception to be independent of age. The results of the present study are in congruence with the latter, where age was not found to significantly influence pain scores of participants. A possible explanation is that though age does not alter pain scores among closely aged individuals, comparison between pain perception between children at different stages of life such as pre-school and adolescence can show notable deviation.

In this study, gender had no impact on the perception of pre-schoolers similar to results obtained by previous studies ${ }^{4,17-20}$. These findings are substantiated by the reports suggesting that children below the age of eight experience pain of equivalent intensities with no gender bias. Similarly, the other factors such as previous experiences of hospitalisation, venepuncture, site of venepuncture and attempts at successful venepuncture were not significantly linked to the pain scores reported by pre-schoolers enrolled in this study $(p>0.05)$. These results share congruity with findings of Manne SL, et $a l^{21}$ who showed that previous brushes with hospitalisation and venepuncture did not significantly alter pain scores. This may be due to fact that the fear and anxiety experienced during previous exposure to 
venepuncture when left untreated, did not help in building pain tolerance among children ${ }^{21}$. The current study was novel in its approach to explore a distraction based procedural management strategy devoid of the side effects noticed in pharmacologic equivalents. Not only do distraction tools like cartoon animation videos serve as a powerful pain alleviant but they also make fear and anxiety oblivious to the young mind. For caregivers, cartoon animations videos are a preferable pain management technique that can free up considerable time and energy spent on pacifying the children, easy to administer, and affordable in addition to demonstrating the highly noteworthy impact of cartoon animations on pain, and raising awareness for the need for such interventions.

Limitations of this study include the small range of age groups considered and non-standardisation of efficiency with which the venepuncture procedure was performed. Future studies can further expound the efficacy of two or more diversion strategies like cartoon animations, video games and toys or with that of behavioural and physical methods by means of a comparative analysis. Concurrently, a multicentric analysis inclusive of a wide range of age groups can add more valuable insights on the scope of cartoon animation videos as a distraction strategy for pain alleviation in children.

\section{Conclusions}

Cartoon animation video was effective as a pain alleviant during venepuncture. No significant association was found between the level of pain perceived by the 3-6 year old children during venepuncture and the selected variables.

\section{References}

1. Maharjan S, Maheswari BU, Maharjan M. Effectiveness of animated cartoon as a distraction strategy on level of pain among children undergoing venepuncture at selected hospital. International Journal of Health Sciences and Research 2017; 7(8):248-52.

2. Wong CL, Lui MMW, Choi KC. Effects of immersive virtual reality intervention on pain and anxiety among paediatric patients undergoing venepuncture: a study protocol for a randomized controlled trial. Trials. 2019; 20:369. https://doi.org/10.1186/s13063-019-3443z

PMid: 31221208 PMCid: PMC6585051

3. Kaheni S, Bagheri-Nesami M, Goudarzian AH, Rezai MS. The effect of video game play technique on pain of venepuncture in children. International Journal of Pediatrics 2016; 4(5): 1795-802.

4. Shrestha R, Jeneta BJJ. A study to evaluate the effectiveness of cartoon based diversional therapy on pain during intravenous medication among preschoolers in selected hospitals, Bangalore. International Journal of Health Sciences and Research 2018; 8(11):185-93.

5. James J, Ghai S, Rao KLN, Sharma N. Effectiveness of "Animated Cartoons" as a distraction strategy on behavioural response to pain perception among children undergoing venepuncture. Nursing and Midwifery Research Journal 2012; 8(3):198-207. https://doi.org/10.33698/NRF0142

6. Bisogni S, Dini C, Olivini N, Ciofi D, Giusti F, Caprilli S, et al. Perception of venepuncture pain in children suffering from chronic diseases. BMC Research Notes 2014; 7:735. https://doi.org/10.1186/1756-0500-7-735 PMid: 25326685 PMCid: PMC4210598

7. Gold JI, Kim SH, Kant AJ, Joseph MH, Rizzo AS. Effectiveness of virtual reality for paediatric pain distraction during IV placement. Cyber Psychology and Behaviour 2006; 9(2):207-12. https://doi.org/10.1089/cpb.2006.9.207 PMid: 16640481

8. Moureau N, Zonderman A. Does it always have to hurt? Premedication for adults and children for use with intravenous therapy. Journal of Intravenous Nursing 2000; 23(4):213-9.

9. Birnie KA, Noel M, Parker JA, Chambers CT, Uman LS, Kisely SR, et al. Systematic review and meta-analysis of distraction and hypnosis for needle related pain and distress in children and adolescents. Journal of Pediatric Psychology 2014; 39(8):783-808. https://doi.org/10.1093/jpepsy/jsu029 PMid: 24891439 PMCid: PMC4138805

10. Bukola IM, Paula D. The effectiveness of distraction as procedural pain management technique in paediatric oncology patients: a meta-analysis and systematic review. Journal of Pain and Symptom Management 2017; 54(4):589-600. 
https://doi.org/10.1016/j.jpainsymman.201 7.07.006

PMid: 28712986

11. Hodgins MJ, Lander J. Children's coping with venepuncture. Journal of Pain and Symptom Management 1997; 13(5):27485.

https://doi.org/10.1016/S08853924(96)003 28-4

12. Devi CP, Shinde J, Patil NB. Effectiveness of animated cartoon video as a distraction strategy on pain perception during and after venepuncture among pre-schoolers. International Journal of Psychiatric Nursing 2017; 3(1):26-31. https://doi.org/10.5958/2395180X.2017.00 005.6

13. Kaur B, Sarin J, Kumar Y. Effectiveness of cartoon distraction on pain perception and distress in children during intravenous injection. IOSR Journal of Nursing and Health Science 2014; 3(3):8-15. https://doi.org/10.9790/1959-03320815

14. Noel M, McMurtry CM, Chambers CT, McGrath PJ. Children's memory for painful procedures: the relationship of pain intensity, anxiety, and adult behaviours to subsequent recall. Journal of Pediatric Psychology 2010; 35(6):62636.

https://doi.org/10.1093/jpepsy/jsp096

PMid: 19889718

15. Costello M, Ramundo M, Christopher NC, Powell KR. Ethyl vinyl chloride vapocoolant spray fails to decrease pain associated with intravenous cannulation in children. Clinical Pediatrics 2006; 45:628-32.

https://doi.org/10.1177/000992280629101 3

PMid: 16928840

16. Gandhar SS, Deshpande J, Borude S. Effectiveness of cartoon movies as distracter on pain among children undergoing venepuncture. International Journal of Science and Research. 2016; 5(6):2241-4.

17. Humphrey GB, Boon CMJ, van Linden van den Heuvell GEFC, van de Wiel HBM. The occurrence of high levels of acute behavioural distress in children and adolescents undergoing routine venepuncture. Pediatrics 1992; 90:87-91.

18. Petrovic P, Petersson KM, Ghatan PH, Stone-Elander S, Ingvar M. Pain related cerebral activation is altered by a distracting cognitive task. Pain 2000; 85:19-30.

https://doi.org/10.1016/S03043959(99)002 $32-8$

19. Cohen LL, Bernard RS, Greco LR, McClellan CB. A child-focused intervention for coping with procedural pain: Are parent and nurse coaches necessary? Journal of Pediatric Psychology 2002; 27:749-57. https://doi.org/10.1093/jpepsy/27.8.749 PMid: 12403865

20. Fowler-Kerry S, Lander JR. Management of injection pain in children. Pain 1987; 30(2):169-75. https://doi.org/10.1016/03043959(87)9107 $2-4$

21. Manne SL, Redd WH, Jacobsen PB, Gorfinkle K, Schorr O, Rapkin B. Behavioural intervention to reduce child and parent distress during venepuncture. Journal of Consulting and Clinical Psychology 1990; 58: 565-72. https://doi.org/10.1037/0022006X.58.5.56 5

PMid: 2254503 